Check for updates

Cite this: RSC Adv., 2019, 9, 24770

Received 17th May 2019

Accepted 26th June 2019

DOI: 10.1039/c9ra03720a

rsc.li/rsc-advances

\title{
High-sulfur coal-derived nitrogen, sulfur dual- doped carbon as an economical metal-free electrocatalyst for oxygen reduction reaction
}

\author{
Jing Geng, ${ }^{a}$ Hui-Juan Zhang, (D) *a Sunwu Yao, ${ }^{a}$ Chunlei Cai, ${ }^{a}$ Zi-Feng Ma, (D) b \\ Jiancheng Wang, ${ }^{c}$ Haibing Wei ${ }^{d}$ and Junhe Yang ${ }^{a}$
}

\begin{abstract}
The search for an economical electrocatalyst for oxygen reduction reaction (ORR) is a worldwide issue for fuel cells and metal-air batteries. Herein, we used cheap and available high-sulfur inferior coal as the single precursor to synthesize an N, S dual-doped carbon (NSC) metal-free electrocatalyst for the ORR. The N, S dual-doped carbon (NSC), prepared at $800{ }^{\circ} \mathrm{C}$ (NSC800), possessed a large specific surface area of $942 \mathrm{~m}^{2}$ $\mathrm{g}^{-1}$, with an amorphous carbon structure and more defects than the others. Furthermore, it contains 1.06 at\% $\mathrm{N}$ and 2.24 at\% $\mathrm{S}$, where $\mathrm{N}$ is resolved into pyridinic- $\mathrm{N}$, pyrrolic-N, and graphitic-N. For the electrochemical behavior, NSC800 displayed a good ORR electrocatalytic activity, with the ORR peak potential at $-0.245 \mathrm{~V}$ (vs. SCE) and half-wave potential $\left(E_{1 / 2}\right)$ at $-0.28 \mathrm{~V}$ (vs. SCE) in an alkaline solution. This study not only gives an original and facile method to prepare an economical ORR electrocatalyst but also provides a novel clean-use of high-sulfur inferior coal.
\end{abstract}

\section{Introduction}

Electrocatalysts for the sluggish and complex oxygen reduction reaction (ORR) at the cathode of fuel cells and metal-air batteries appear particularly important as this reaction can determine the performances of these systems. ${ }^{1-3}$ At present, the commercial ORR electrocatalysts are still carbon-supported precious metal platinum-based electrocatalysts. However, due to the limited supply and easy CO-poisoning of platinum, the search for non-precious metal or even metal-free electrocatalysts for the ORR seems necessary.

In recent years, carbon materials doped with metal-free heteroatoms, such as nitrogen $(\mathrm{N}),{ }^{4,5}$ phosphorus $(\mathrm{P}),{ }^{6,7}$ sulfur $(\mathrm{S}),{ }^{8,9}$ boron (B), ${ }^{10,11}$ and fluorine $(\mathrm{F}),{ }^{12,13}$ were demonstrated to be one of the most promising substitutes to carbon-supported noble metal platinum and its alloy electrocatalysts for the ORR in an alkaline solution. Moreover, the carbon materials dual-doped with these heteroatoms displayed a better ORR electrocatalytic activity owing to the synergistic effects of these dopants. ${ }^{6-9,11-16}$ Nevertheless, the large-scale application of these materials is presently impossible as most heteroatom-

\footnotetext{
${ }^{a}$ School of Materials Science and Engineering, The University of Shanghai for Science and Technology, Shanghai, China.E-mail: hjzhang@usst.edu.cn

${ }^{b}$ Department of Chemical Engineering, Shanghai Jiaotong University, Shanghai, China 'State Key Laboratory Breeding Base of Coal Science and Technology Co-founded by Shanxi Province and the Ministry of Science and Technology, Taiyuan University of Technology, Shanxi, China
}

${ }^{d}$ Key Laboratory of Advanced Functional Materials and Devices of Anhui Province, Hefei University of Technology, Hefei, 230009, China containing precursors are toxic and flammable along with their complicated and environmentally unfriendly synthesis routes. Hence, the search for heteroatom-containing precursors in abundant resource and at much low-cost is an important and urgent necessity for the actual application of clean and renewable energy conversion and storage systems.

Fortunately, coal, the most abundant fossil fuel resource in the world, essentially contains high contents of $\mathrm{N}$, S-containing heterocyclic chemicals, for instance, pyridine, quinoline, thiophene, and their derivatives. These compounds, being extremely difficult to be utilized or even removed, can often cause serious environmental pollution during the direct combustion of raw coal. Thus, methods to prepare value-added products from raw coal, especially low-cost inferior coal, have become particularly important. To the best of our knowledge, till date, little has been reported on coal-based ORR electrocatalysts ${ }^{17-21}$ and only a few researchers have utilized the downstream products of coal, such as coal tar, ${ }^{22}$ coal tar pitch, ${ }^{23}$ and coal liquefaction residues, ${ }^{24}$ to prepare the ORR metal-free electrocatalysts. For example, Masatoshi Nagai et al. used different raw coals, namely the Australia brown coal and the Vietnam anthracite coal, to prepare non-precious metal ORR electrocatalysts by $\mathrm{N}$-doping at $673-1123 \mathrm{~K}$ in an $\mathrm{NH}_{3}$ atmosphere. ${ }^{\mathbf{1 7 - 2 0}}$ Recently, to synthesize non-precious metal ORR electrocatalysts, Chen et al. first pre-treated the brown coal using different acids and then doped $\mathrm{N}$ at $800{ }^{\circ} \mathrm{C}$ in an $\mathrm{NH}_{3}$ atmosphere. ${ }^{21}$

The high-sulfur coal, a kind of inferior coal with the sulfur content greater than $3 \%$, has a much lower price than the brown coal and anthracite coal. Furthermore, the high content of $\mathrm{N}$ and $S$ in high-sulfur coal is a precondition of the direct preparation of $\mathrm{N}, \mathrm{S}$ dual-doped carbon. Therefore, in this study, we 
applied this inferior high-sulfur coal as the single cheap precursor to synthesize N, S dual-doped carbon (NSC) and estimated their ORR electrocatalytic performances in alkaline media. Further, the influence of activating temperature on the morphology, structure, chemical composition, and electrochemical performance were characterized and investigated. In this way, it not only gave an original and facile method to prepare the economical ORR electrocatalyst but also provided a novel clean-use of raw coal.

\section{Experimental}

The preparation process of the NSC electrocatalyst is illustrated in Fig. 1. The high-sulfur coal (Linfen mine company, Shanxi, China) was chosen as the starting material and ball-milled into a powder form at $350 \mathrm{rpm}$ for $4 \mathrm{~h}$. There were two steps to prepare the NSC electrocatalyst: the first one is $\mathrm{KOH}$ activation and the second one is acid leaching. In a typical synthesis, $1.0 \mathrm{~g}$ of $\mathrm{KOH}$ (an activating agent) was dissolved in $10 \mathrm{~mL}$ of ethanol. Then, $0.5 \mathrm{~g}$ high-sulfur coal (the mass ratio of coal to $\mathrm{KOH}$ was 1:2) was added into the above solution. After stirring the solution mixture for $2 \mathrm{~h}$ at room temperature, it was dried at $80{ }^{\circ} \mathrm{C}$ in a vacuum oven. Subsequently, in a $\mathrm{N}_{2}$ atmosphere, the obtained powder was activated at $600{ }^{\circ} \mathrm{C}, 700{ }^{\circ} \mathrm{C}, 800{ }^{\circ} \mathrm{C}$, and $900{ }^{\circ} \mathrm{C}$ for $90 \mathrm{~min}$. At last, the sample was leached in $1 \mathrm{M} \mathrm{HCl}$ solution under ultrasonic condition, followed by filtration and washing with deionized water, and subsequent freeze-drying to obtain the N, S dual-doped carbon (NSC). The obtained samples were named as NSC600, NSC700, NSC800, and NSC900, where the numbers stand for the activated temperature.

The morphology of the NSC sample was determined via the field emission scanning electron microscopy (FESEM, FEI, Quanta FEG 450). The $\mathrm{N}_{2}$ adsorption-desorption isotherm curves were determined using an ASAP 2020-Physisorption Analyzer (Micromeritics, USA). The X-ray diffraction (XRD) patterns were recorded on a Germany Bruker D8-Advance X-ray diffractometer using $\mathrm{Cu} \mathrm{K} \alpha$ radiation $(\lambda=0.154 \mathrm{~nm})$ at $40 \mathrm{~mA}$ and $40 \mathrm{kV}$. The Raman spectra were obtained using $532 \mathrm{~nm}$ laser excitation on a LabRAM HR Evolution. The elemental analysis of the NSC sample was recorded by X-ray photoelectron spectroscopy (XPS) on PerkinElmer PHI 3056 with an Al Ka monochromatic radiation.

The electrocatalyst ink was fabricated by dispersing $2.0 \mathrm{mg}$ electrocatalyst into the solution mixture containing $380 \mu \mathrm{L}$ of deionized water and $20 \mu \mathrm{L}$ (5 wt\%) of Nafion solution under ultrasonic condition. Then, the working electrode was prepared by drying $20 \mu \mathrm{L}$ of the above ink on the surface of a glassy carbon electrode (AFE7R9GCPT, Pine Instruments) at room temperature.

Electrochemical measurements were performed using several technologies, such as cyclic voltammetry (CV), rotating disk electrode (RDE), and rotating ring-disk electrode (RRDE) techniques in a three-electrode system, consisting of the reference electrode (a KCl-saturated calomel electrode, SCE), the counter electrode (a Pt wire), and the working electrode (prepared as mentioned above). All the potentials reported here were referred to the SCE potential, and the potential scan rate was $5 \mathrm{mV} \mathrm{s}^{-1}$. CVs were obtained in an $\mathrm{N}_{2}$-saturated and an $\mathrm{O}_{2}$ saturated $0.1 \mathrm{M} \mathrm{KOH}$ solution after pre-sweeping the working electrode several times. Both the RDE and RRDE polarization curves were obtained at a rotation rate of $900 \mathrm{rpm}$ in an $\mathrm{O}_{2}$ saturated $0.1 \mathrm{M} \mathrm{KOH}$ solution, where the ring currents were recorded at the disk potential of $0.5 \mathrm{~V}$.

\section{Results and discussion}

Fig. 2a shows the SEM image of NSC800. It can be seen that NSC800 consists of irregular particles, exhibiting a thick block structure. Further, the TEM images were captured to analyze the microstructure of NSC800. The amorphous carbon in the thin and large nanosheets consisting of randomly orientated graphitic domains can be mainly observed in the TEM images (Fig. $2 \mathrm{~b}$ and $\mathrm{c}$ ).



Fig. 1 Schematic of fabrication for the NSC electrocatalysts derived from high-sulfur inferior coal as the single N, S and C precursor. 




Fig. 2 Typical (a) SEM, (b and c) TEM images of NSC800.

To investigate the pore property of NSC800, the $\mathrm{N}_{2}$ adsorption-desorption isotherm curves, as shown in Fig. 3a, were recorded. The figure reveals that these isotherm curves were characteristic of type I monolayer adsorption, where the $\mathrm{N}_{2}$ rapid adsorption appears at a very low $P / P_{0}$, suggesting that there exist abundant micropores..$^{18,23-25}$ This phenomenon was further approved by the curve of the pore size distribution shown in the inset. ${ }^{25}$ It indicates that there were lots of micropores $(<2 \mathrm{~nm})$ in NSC800, which cannot be measured by SEM. In addition, mainly due to the micropores, NSC800 showed a specific surface area of $942 \mathrm{~m}^{2} \mathrm{~g}^{-1}$. The structures of the NSC electrocatalysts were further investigated by X-ray diffraction (XRD). As shown in Fig. 3b, there were two broad and weak diffraction peaks at around $2 \theta=26^{\circ}$ and $43^{\circ}$ for each sample, corresponding to the (002) and (100) diffraction peaks of graphitic carbon. ${ }^{20,21,23,24}$ Furthermore, the intensity of these diffraction peaks became weaker as the annealing temperature was increased. This indicates that the high-sulfur coal-derived NSC electrocatalysts were amorphous and had a highly disordered structure.
To further understand the structural characters of these NSC prepared at different temperatures, Raman spectra are given in Fig. 4. Each spectrum can be divided into two main bands by the curve-fittings: (1) the main D band, located at about $1350 \mathrm{~cm}^{-1}$, was attributed to the disordered structure, such as defects and heteroatoms; and (2) the main $\mathrm{G}$ band at $1590 \mathrm{~cm}^{-1}$ was ascribed to the vibration mode of an intact graphitic lattice with $E_{2 \mathrm{~g}}$ symmetry. ${ }^{26,27}$ From the Raman spectra analysis, as listed in Table 1, here, we take three means to give a qualitative information regarding the comparison of the degree of defects, which is the ratio of intensity $\left(I_{\mathrm{D}} / I_{\mathrm{G}}\right)$, ratio of area $\left(A_{\mathrm{D}} / A_{\mathrm{G}}\right)$ and ratio of width at half maxima $\left(W_{\mathrm{D}} / W_{\mathrm{G}}\right)$. Moreover, the values of these ratios were found to be $1.00,2.31$, and 2.31 for NSC600, $0.99,2.17$, and 2.14 for NSC700, 1.04, 2.42, and 2.52 for NSC800, $1.03,2.21$, and 2.25 for NSC900, respectively. Based on these three parameters, NSC800 was found to have the largest value, indicating that it possesses more defect than the others.

To confirm the elemental composition and state, NSC800 was studied by XPS, as shown in Fig. 5. The XPS survey spectrum of NSC800 in Fig. 5a exhibits four peaks at about $284.8 \mathrm{eV}, 400.1 \mathrm{eV}$,

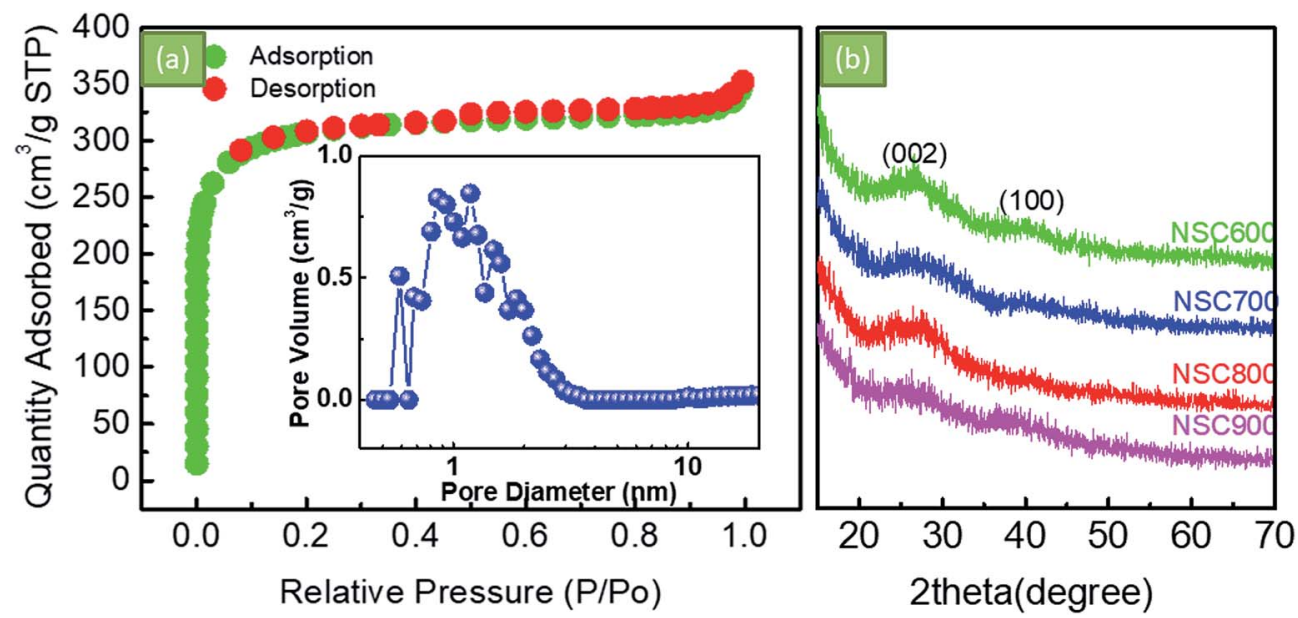

Fig. 3 (a) The $\mathrm{N}_{2}$ adsorption-desorption isotherm curves and the corresponding pore size distribution of NSC800. (b) The XRD patterns of the as-prepared NSC electrocatalysts. 


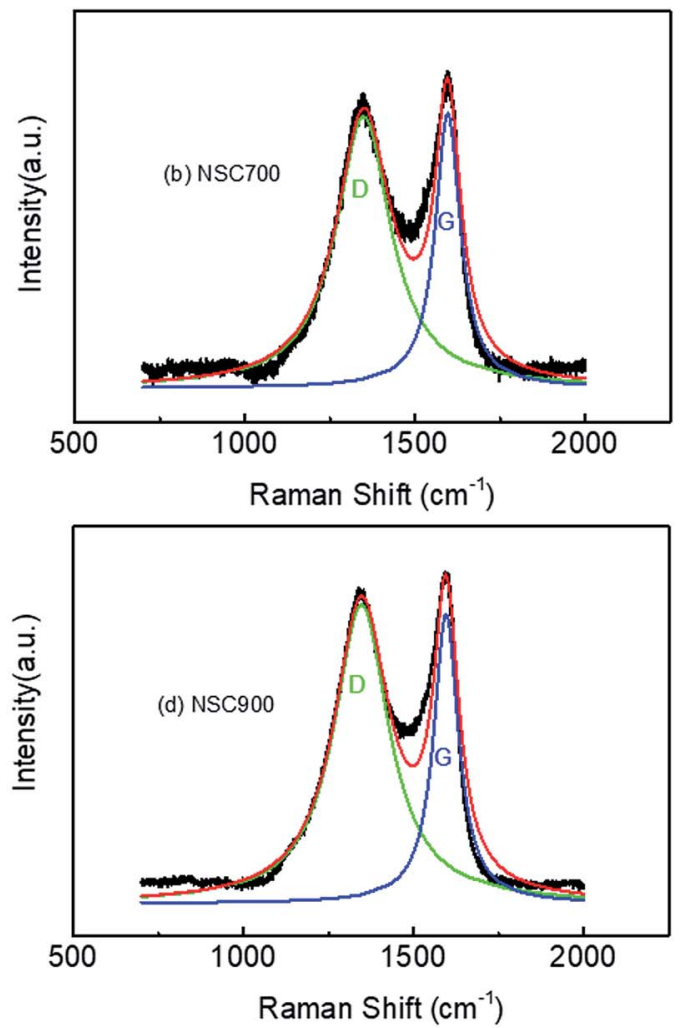

Fig. 4 The Raman spectra with the fittings of the as-prepared (a) NSC600, (b) NSC700, (c) NSC800 and (d) NSC900 electrocatalysts.

$164.0 \mathrm{eV}$, and $534.6 \mathrm{eV}$, assigned to $\mathrm{C} 1 \mathrm{~s}, \mathrm{~N} 1 \mathrm{~s}, \mathrm{~S} 2 \mathrm{p}$, and $\mathrm{O} 1 \mathrm{~s}$, respectively. Concretely, the surface atomic percentage of $\mathrm{C}, \mathrm{N}, \mathrm{S}$, and $\mathrm{O}$ in NSC800 were determined to be $73.7 \%, 1.06 \%, 2.24 \%$, and $23.0 \%$, respectively, demonstrating the successful heteroatom doping of $\mathrm{N}$ and $\mathrm{S}$ into the carbon framework, which is regarded as one of the contributors to the ORR electrocatalytic activity. ${ }^{\mathbf{1 , 3 , 8}, 9}$ Specifically, the high-resolution XPS spectrum of C 1s (Fig. 5b) can be resolved into four components: the typical C-C $(284.4 \mathrm{eV}), \mathrm{C}-\mathrm{S}$ (285.0 eV), C-N (286.0 eV), and C-O (288.3 eV)..$^{\mathbf{8 , 9}, 28}$ In a similar way, the high-resolution XPS spectrum of $\mathrm{N}$ 1s (Fig. 5c) can be resolved into three components: pyridinic-N (398.7 eV), pyrrolic-N $(400.1 \mathrm{eV})$, and graphitic-N (401.9 eV) with their proportion being $36.47 \%$, $34.09 \%$, and $29.44 \%$, respectively. ${ }^{21-24,29}$ Likewise, the highresolution XPS spectrum of $\mathrm{S} 2 \mathrm{p}$ (Fig. $5 \mathrm{~d}$ ) can be resolved into three predominate peaks at $164.0 \mathrm{eV}(-\mathrm{C}-\mathrm{S}-\mathrm{C}-), 165.1 \mathrm{eV}(-\mathrm{C}=\mathrm{S})$, and $168.8 \mathrm{eV}\left(-\mathrm{C}-\mathrm{SO}_{x}-\mathrm{C}-\right)$ with the percentage of proportion being $44.43 \%, 30.54 \%$, and $25.03 \%$, respectively. ${ }^{22,23,29}$ From the highresolution XPS spectra of $\mathrm{N} 1 \mathrm{~s}$ and $\mathrm{S} 2 \mathrm{p}$, it can be understood

Table 1 Raman fittings for the NSC electrocatalysts prepared at different pyrolyzed temperatures

\begin{tabular}{llllll}
\hline Electrocatalysts & D band & G band & $I_{\mathrm{D}} / I_{\mathrm{G}}$ & $W_{\mathrm{D}} / W_{\mathrm{G}}$ & $A_{\mathrm{D}} / A_{\mathrm{G}}$ \\
\hline NSC600 & $1353 \mathrm{~cm}^{-1}$ & $1592 \mathrm{~cm}^{-1}$ & 1.00 & 2.31 & 2.31 \\
NSC700 & $1348 \mathrm{~cm}^{-1}$ & $1596 \mathrm{~cm}^{-1}$ & 0.99 & 2.17 & 2.14 \\
NSC800 & $1347 \mathrm{~cm}^{-1}$ & $1590 \mathrm{~cm}^{-1}$ & 1.04 & 2.42 & 2.52 \\
NSC900 & $1347 \mathrm{~cm}^{-1}$ & $1595 \mathrm{~cm}^{-1}$ & 1.03 & 2.21 & 2.25
\end{tabular}

that both $\mathrm{N}$ and $\mathrm{S}$ were successfully incorporated into the amorphous carbon matrix, and all of these elements were evolved from high-sulfur coal precursor.

To study the ORR electrocatalytic activities, CVs of these NSC samples were first examined in an $\mathrm{N}_{2}$-saturated and $\mathrm{O}_{2}$-saturated 0.1 $\mathrm{M} \mathrm{KOH}$ solution. In Fig. 6, we can see the featureless CVs (dot lines) for each sample in the $\mathrm{N}_{2}$-saturated electrolyte. Nevertheless, if the electrolyte was $\mathrm{O}_{2}$-saturated, the obvious cathodic ORR peaks were observed for these NSC, indicating their enhanced ORR electrocatalytic activities. In general, the ORR electrocatalytic activity was found to increase gradually with an increase in the annealing temperature. Specifically, the ORR peak potential and the current of NSC800 were present at a positive position: $-0.245 \mathrm{~V}$ and $0.085 \mathrm{~mA}$, respectively, which were much higher than those of NSC600 $(-0.298 \mathrm{~V}$ and 0.046 $\mathrm{mA})$, NSC700 ( $-0.276 \mathrm{~V}$ and $0.054 \mathrm{~mA})$, and NSC900 $(-0.276 \mathrm{~V}$ and $0.049 \mathrm{~mA}$ ), demonstrating that the activation temperature can impact their electrocatalytic activities severely. It also clearly indicates that the elements of $\mathrm{N}$ and $\mathrm{S}$ (harmful) in high-sulfur coal, used for the ORR electrocatalysts, can be environmentfriendly. Incidentally, this result was better than that for NSCNTs1 (-0.29 V vs. Ag/AgCl), NS-CNTs2 (-0.27 V vs. Ag/AgCl), and NS-CNTs3 $(-0.24 \mathrm{~V}$ vs. $\mathrm{Ag} / \mathrm{AgCl})$, which were prepared from coal tar. ${ }^{22}$ In addition, it was also better than other $\mathrm{N}, \mathrm{S}$ dual-doped carbon materials, such as N/S-GP $(-0.35 \mathrm{~V} v s . \mathrm{Ag} /$ $\mathrm{AgCl})^{30}$ and MWCNT@S-N-C $(-0.27 \mathrm{~V} v s . \mathrm{Ag} / \mathrm{AgCl}) .{ }^{31}$

The RDE curves were then measured to obtain an understanding of the ORR process in the presence of these NSC electrocatalysts. In 



Fig. 5 (a) The XPS survey spectrum, the high-resolution XPS spectra of (b) C 1s, (c) N 1s, and (d) S 2p of NSC800.

Fig. 7a, for each sample, there is no well-defined diffusion-limiting current plateau, indicating that the ORR occurs only at the outer layer of the electrocatalyst. Remarkably, at all the studied disk potentials, NSC800 showed a more positive potential than that of the other three samples, such as the half-wave potential $\left(E_{1 / 2}\right)$ and

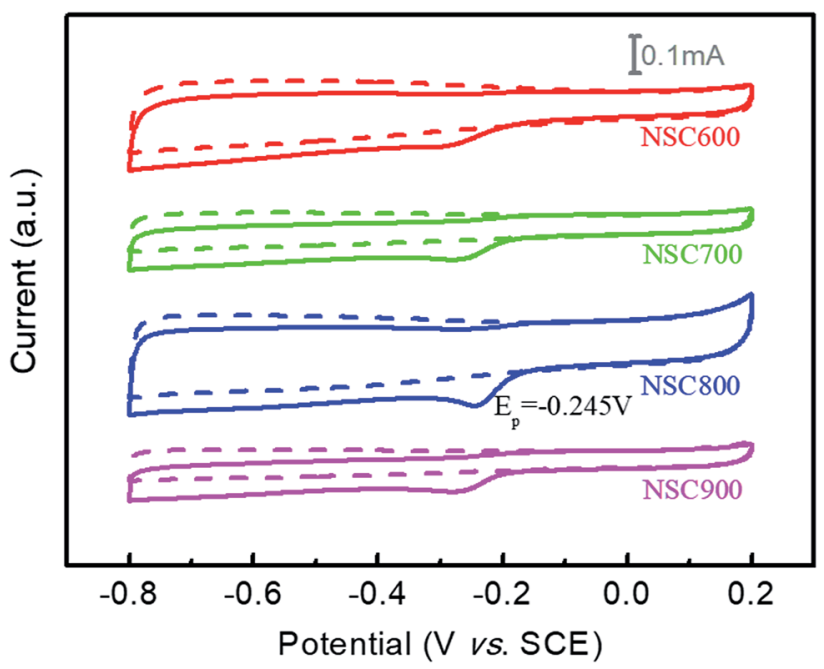

Fig. $6 \mathrm{CVs}$ of these NSC electrocatalysts in $\mathrm{N}_{2}$-saturated (dot lines) and $\mathrm{O}_{2}$-saturated (solid line) $0.1 \mathrm{M} \mathrm{KOH}$ solution at a scan rate $5 \mathrm{mV}$ $\mathrm{s}^{-1}$. diffusion-limiting current, which is in good agreement with the CVs. Specifically, it can be found that the $E_{1 / 2}(-0.28 \mathrm{~V})$ and diffusion-limiting current $(-0.78 \mathrm{~mA})$ of NSC800 were higher than those of the other three NSCs, further confirming the superior ORR activity of NSC800. The RRDE testing was also applied to investigate the ring currents of these NSC electrocatalysts. As shown in Fig. 7b, the ring currents of NSC600, NSC700, and NSC800 were noticeable, while that of NSC900 was quite low, implying that increasing the pyrolysis temperature decreased the ring current. Furthermore, the ring current was dependent on the disk potential with a mountainshaped curve for each sample, where the maximum ring current appeared in the range of $-0.5 \mathrm{~V}$ to $-0.4 \mathrm{~V}$ with an increase in the pyrolysis temperature.

The number of electrons transferred per $\mathrm{O}_{2}(n)$ and the percentage of $\mathrm{HO}_{2}{ }^{-}$yielded $\left(\mathrm{HO}_{2}{ }^{-} \%\right)$ were calculated by the following equations to further study the ORR reaction pathway happening on these NSC electrocatalysts:

$$
\begin{gathered}
n=4 \times \frac{I_{\mathrm{d}}}{\frac{I_{\mathrm{r}}}{N}+I_{\mathrm{d}}} \\
\mathrm{HO}_{2}^{-\%}=200 \times \frac{\frac{I_{\mathrm{r}}}{N}}{\frac{I_{\mathrm{r}}}{N}+I_{\mathrm{d}}}
\end{gathered}
$$



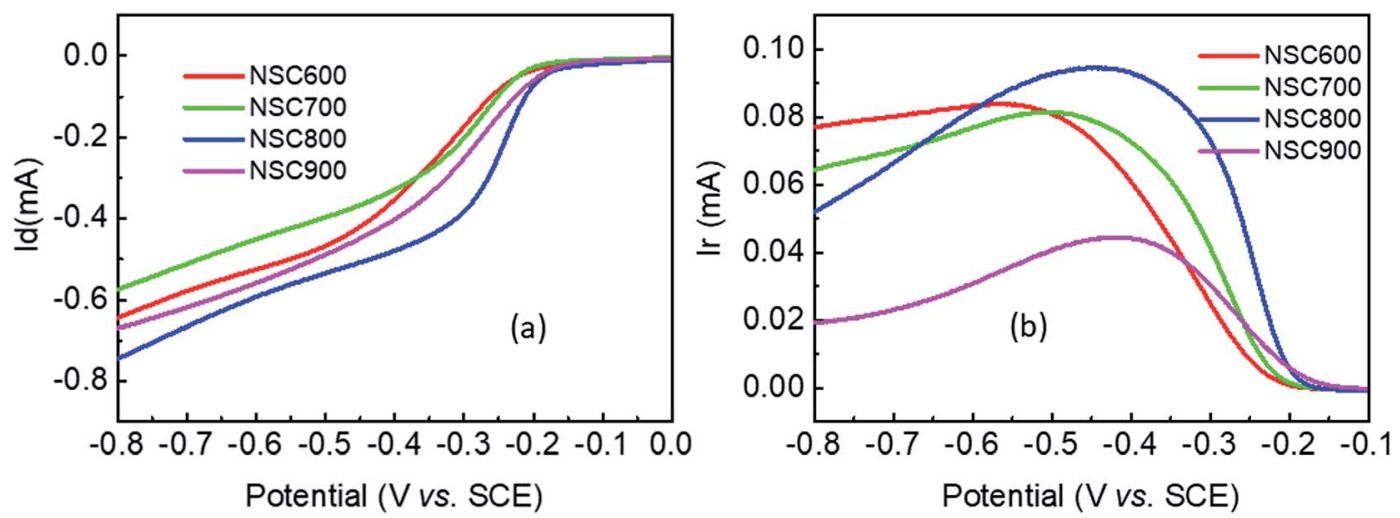

Fig. 7 (a) RDE and (b) RRDE voltammograms of these NSC electrocatalysts in $\mathrm{O}_{2}$-saturated $0.1 \mathrm{M} \mathrm{KOH}$ solution at a rotation rate of 900 rpm and a scan rate of $5 \mathrm{mV} \mathrm{s}^{-1}$


Fig. 8 (a) The number of electron-transferred for per $\mathrm{O}_{2}(n)$, and (b) the percentage of $\mathrm{HO}_{2}{ }^{-}$yield $\left(\mathrm{HO}_{2}{ }^{-} \%\right)$ obtained from the RDE and RRDE curves for these NSC electrocatalysts.

where, $I_{\mathrm{d}}$ and $I_{\mathrm{r}}$ are the currents of the disk electrode and the ring electrode, respectively, and $N(0.37)$ is the collection efficiency of the ring electrode. In Fig. 8a, these NSC electrocatalysts exhibit the value of $n$ between 2.5 and 4.0, illustrating that the ORR on these NSC electrocatalysts mainly occurred by using the combination of two-electron and four-electron pathway. In addition, the value of $n$ increases evidently when the disk potential decreases. Similarly, the value of $n$ also increases as the pyrolysis temperature increases. Correspondingly, for $\mathrm{HO}_{2}{ }^{-} \%$ in Fig. 8b, it was found to be in between $10 \%$ and $70 \%$, further verifying that the reaction pathway of the ORR on these NSC electrocatalysts was a mixed two-electron and four-electron reaction. Also, the $\mathrm{HO}_{2}{ }^{-} \%$ was dependent on the disk potential and pyrolysis temperature, namely, it evidently decreases when the disk potential decreases and the pyrolysis temperature increases.

\section{Conclusions}

In conclusion, we have successfully prepared economic NSC electrocatalysts for the ORR via the pyrolysis of high-sulfur inferior coal as the single cheap source, indicating that this two environmentally unfriendly elements can be clean-used to prepare a valuable product. The Raman spectra indicated that NSC800 possessed more defect than the others, and has a specific surface area of $942 \mathrm{~m}^{2} \mathrm{~g}^{-1}$. XPS shows that NSC800 contains $\mathrm{N}$ and $\mathrm{S}$ with the atomic percentage of $1.06 \%$ and $2.24 \%$, respectively. Furthermore, $\mathrm{N}$ can be resolved into pyridinic-N, pyrrolic-N, and graphitic-N. The electrochemical measurements indicated that NSC800 has a good ORR electrocatalytic activity in an alkaline medium with the ORR peak potential at $-0.245 \mathrm{~V}$ and a half-wave potential $\left(E_{1 / 2}\right)$ at $-0.28 \mathrm{~V}$ on a mixed of two-electron and four-electron pathways. Thus, this study not only gives an original and facile method to prepare economical ORR electrocatalysts but also provides a novel clean-use of high-sulfur inferior coal.

\section{Conflicts of interest}

There are no conflicts among all the authors to declare.

\section{Acknowledgements}

We are grateful for the support from the National Natural Science Foundation of China (No. 21406139), the Project from the University of Shanghai for Science and Technology (No. 
2017KJFZ009), the State Key Laboratory Breeding Base of Coal Science and Technology Co-founded by Shanxi Province and the Ministry of Science and Technology, Taiyuan University of Technology, the Open Foundation of Key Laboratory of Advanced Functional Materials and Devices of Anhui Province(No. 4500-411104/011).

\section{References}

1 L. Dai, Y. Xue, L. Qu, H. J. Choi and J. B. Baek, Chem. Rev., 2015, 115, 4823-4892.

2 M. H. Shao, Q. W. Chan, J. P. Dodelet and R. Chenitz, Chem. Rev., 2016, 116, 3594-3657.

3 G. Wu, Front. Energy, 2017, 11, 286-298.

4 E. Bayram, G. Yilmaz and S. Mukerjee, Appl. Catal., B, 2016, 192, 26-34.

5 B. He, F. Liu and S. Yan, J. Mater. Chem. A, 2017, 5, 1806418070.

6 G. Zhao, L. Shi, J. Xu, X. Yan and T. S. Zhao, Int. J. Hydrogen Energy, 2018, 43, 1470-1478.

7 W. Wang, J. Li, Y. Kang, F. Wang, J. Song and Z. Lei, Electrochim. Acta, 2017, 248, 11-19.

8 J. M. Chabu, L. Wang, F. Y. Tang, K. Zeng, J. Sheng, M. D. Walle, L. Deng and Y. N. Liu, ChemElectroChem, 2017, 4, 1885-1890.

9 W. Zhang, Y. S. He, S. Zhang, X. Yang, X. Yuan and Z. F. Ma, Electrochem. Commun., 2017, 81, 34-37.

10 L. Wang, H. Dong, Z. Guo, L. Zhang, T. Hou and Y. Li, J. Phys. Chem. C, 2016, 120, 17427-17434.

11 J. S. Han, D. Y. Chung, D. G. Ha, J. H. Kim, K. Choi, Y. E. Sung and S. H. Kang, Carbon, 2016, 105, 1-7.

12 H. J. Zhang, S. Yao, J. Geng, Z. F. Ma and J. Yang, J. Colloid Interface Sci., 2019, 535, 436-443.

13 H. J. Zhang, X. Zhang, S. Yao, H. Hu, Z. F. Ma and J. Yang, J. Electrochem. Soc., 2017, 164, H1081-H1085.

14 Y. Dong, M. Zhou, W. Tu, E. Zhu, Y. Chen, Y. Zhao, S. Liao, Y. Huang, Q. Chen and Y. Li, Adv. Funct. Mater., 2019, 1900015.
15 X. Peng, L. Zhang, Z. Chen, L. Zhong, D. Zhao, X. Chi, X. Zhao, L. Li, X. Lu, K. Leng, C. Liu, W. Liu, W. Tang and K. P. Loh, Adv. Mater., 2019, 1900341.

16 X. Li, B. Guan, S. Gao and X. W. Lou, Energy Environ. Sci., 2019, 12, 648-655.

17 M. Muraoka and M. Nagai, Fuel, 2012, 94, 204-210.

18 M. Muraoka, H. Tominaga and M. Nagai, Fuel, 2012, 97, 211218.

19 M. Muraoka, H. Tominaga and M. Nagai, Fuel, 2012, 102, 359-365.

20 S. M. Shamsunnahar and M. Nagai, Fuel, 2014, 126, 134-136.

21 X. Chen, X. Huang, T. Wang, S. Barwe, K. Xie, Y. U. Kayran, D. Wintrich, W. Schuhmann and J. Masa, Electrochim. Acta, 2016, 211, 568-575.

22 Z. Liu, X. Fu, X. Wei and F. Peng, J. Mater. Chem. A, 2015, 3, 22723-22729.

23 D. Yu, L. Zhou, J. Tang, J. Li, J. Hu, C. Peng and H. Liu, Ind. Eng. Chem. Res., 2017, 56, 8880-8887.

24 L. Zhao, Y. Wang and W. Li, RSC Adv., 2016, 6, 90076-90081. 25 Y. Zhao, X. Li, X. Jia and S. Gao, Nano Energy, 2019, 58, 384391.

26 Z. Zhuang, Y. Cui, H. Zhu, Y. Shi and Q. Zhuang, J. Electrochem. Soc., 2015, 165, A2225-A2232.

27 D. Yan, Y. Li, J. Huo, R. Chen, L. Dai and S. Wang, Adv. Mater., 2017, 29, 1606459.

28 T. Jiang, Y. Wang, K. Wang, Y. Liang, D. Wu, P. Tsiakaras and S. Song, Appl. Catal., B, 2016, 189, 1-11.

29 C. V. Pham, M. Klingele, B. Britton, K. R. Vuyyuru, T. Unmuessig, S. Holdcroft, A. Fischer and S. Thiele, Adv. Sustainable Syst., 2017, 1, 1600038.

30 T. Akhter, M. M. Islam, S. N. Faisal, E. Haque, A. I. Minett, H. K. Liu, K. Konstantinov and S. X. Dou, ACS Appl. Mater. Interfaces, 2016, 8, 2078-2087.

31 Q. Zhu, L. Lin, Y. F. Jiang, X. Xie, C. Z. Yuan and A. W. Xu, New J. Chem., 2015, 39, 6289-6296. 